2018-05

\title{
Microplastics in sub-surface waters of the Arctic Central Basin
}

\author{
Kanhai, LDK
}

http://hdl.handle.net/10026.1/11255

10.1016/j.marpolbul.2018.03.011

Marine Pollution Bulletin

Elsevier BV

All content in PEARL is protected by copyright law. Author manuscripts are made available in accordance with publisher policies. Please cite only the published version using the details provided on the item record or document. In the absence of an open licence (e.g. Creative Commons), permissions for further reuse of content should be sought from the publisher or author. 
Microplastics in sub-surface waters of the Arctic Central Basin

2 La Daana K. Kanhai ${ }^{\mathrm{a}, \mathrm{b}^{*}}$, Katarina Gardfeldt ${ }^{\mathrm{c}}$, Olga Lyashevska ${ }^{\mathrm{a}}$, Martin Hassellöv ${ }^{\mathrm{d}}$, Richard C.

3 Thompson $^{\mathrm{b}}$, Ian O’Connor ${ }^{\mathrm{a}}$

$4{ }^{\mathrm{a}}$ Marine and Freshwater Research Centre, Galway Mayo Institute of Technology, Dublin Road,

5 Galway, Ireland

$6{ }^{b}$ Marine Biology and Ecology Research Centre, School of Biological and Marine Sciences,

7 Plymouth University, Drake Circus, Plymouth, Devon PL4 8AA, United Kingdom

8 'Department of Chemistry and Chemical Engineering, Chalmers University of Technology,

9 Göteborg, SE-412 96, Sweden

10 Department of Chemistry and Molecular Biology, University of Gothenburg, Göteborg, Sweden

\section{Abstract}

13 Polar oceans, though remote in location, are not immune to the accumulation of plastic debris. The 14 present study, investigated for the first time, the abundance, distribution and composition of 15 microplastics in sub-surface waters of the Arctic Central Basin. Microplastic sampling was carried 16 out using the bow water system of icebreaker Oden (single depth: $8.5 \mathrm{~m}$ ) and CTD rosette sampler

17 (multiple depths: $8-4369 \mathrm{~m}$ ). Potential microplastics were isolated and analyzed using Fourier 18 Transform Infrared Spectroscopy (FT-IR). Bow water sampling revealed that the median 19 microplastic abundance in near surface waters of the Polar Mixed Layer (PML) was 0.7 particles $20 \mathrm{~m}^{-3}$. Regarding the vertical distribution of microplastics in the ACB, microplastic abundance 21 (particles $\left.\mathrm{m}^{-3}\right)$ in the different water masses was as follows: Polar Mixed Layer $(0$ - 375) > Deep 22 and bottom waters $(0-104)>$ Atlantic water $(0-95)>$ Halocline i.e. Atlantic or Pacific $(0-83)$. 


\section{Keywords}

25 Microplastic, Marine debris, Arctic Ocean, Sub-surface waters, Pollution, Water column

$27 *$ Corresponding Author

28 Email Address: ladaana.kanhai@ research.gmit.ie

Introduction

31 The Arctic Ocean, though the smallest in the world, is unique due to its distinct abiotic features

32 and the highly specialised ecosystem it supports. Key anthropogenic drivers which may put

33 pressure on this ecosystem include (i) climate change, (ii) harvest and fisheries, (iii) persistent,

34 bio-accumulative and toxic contaminants, (iv) industrial development, (v) shipping, and (vi)

35 invasive alien species (CAFF 2017). Plastic contaminants in the world's oceans have emerged as

36 an issue of global importance due to their ubiquitous distribution, long-range transport potential,

37 persistence and perhaps most importantly the potential threat they pose to marine organisms

38 (UNEP 2011). Remote polar oceans such as the Arctic Ocean have not been immune to the entry

39 of plastics as a combination of long-range transport processes and local anthropogenic activities

40 have contributed to the plastic debris in these areas.

41

42 Characteristic abiotic features which set the Arctic Ocean apart from other oceanic basins include

43 (i) a central area of perennial pack ice, (ii) seasonal extremes in solar irradiance, ice and snow

44 cover, temperature and riverine inflow, and (iii) an upper layer of lower salinity water due to

45 freshwater input from rivers and seasonal sea-ice melt (CAFF 2013). This unique ecosystem is a

46 habitat for a vast array of marine organisms, some of which are (i) endemic to the region, (ii) 
47 commercially important, (iii) apex predators, (iv) central to the functioning of the ecosystem, and

48 (v) threatened as evidenced by their inclusion in the IUCN Red List of Threatened Species (CAFF 2013, CAFF 2017).

50

51 Despite its remote location away from major population centres and the low coastal population in 52 its surrounding shelf areas, both macro and microplastics were detected in the various 53 environmental compartments of the Arctic Ocean. Between 2002 and 2014, macroplastics were 54 detected on the seafloor (2500 m depth) of the eastern Fram Strait at the HAUSGARTEN 55 observatory (Bergmann and Klages 2012; Tekman et al. 2017). Sightings of buoyant macroplastics 56 were also made during ship and helicopter observation surveys in the Barents Sea and Fram Strait 57 (Bergmann et al. 2016). A citizen-science study also recently reported the presence of macroplastics on six beaches of the Svalbard Archipelago (Bergmann et al. 2017a). Arctic sea ice 59 was reported by Obbard et al. (2014) as having microplastic concentrations (38- 234 particles $\mathrm{m}^{3}$ 60 of ice) several orders of magnitude greater than highly contaminated oceanic waters. Lusher et al. 61 (2015) first reported on microplastic abundances in surface and sub-surface waters south and 62 southwest of Svalbard. Amélineau et al. (2016) later reported on microplastic abundance in surface 63 waters east of Greenland. Regarding Arctic species, microplastics have been detected in the gular 64 pouches of Little Aulks (Alle Alle), (Amélineau et al. 2016), as well as in the stomachs of juvenile 65 polar cod (Boreogadus saida), (Kuhn et al. 2018). Microplastics were also detected in sediments 66 (collection depths 2340 - 5570 m) from the Fram Strait (Bergmann et al. 2017b). Recently, results 67 from a circumpolar expedition of the Arctic indicated that concentrations of floating plastic ranged 68 between $0-320000$ items $\mathrm{km}^{-2}$ in the Greenland and Barents Sea and $0-27000$ items $\mathrm{km}^{-2}$ in 69 the rest of the Arctic Ocean (Cózar et al. 2017). 
71 Plastic contaminants are introduced to the Arctic Ocean due to a combination of (i) long-range

72 transport processes, e.g. via oceanic currents, biotransport and riverine input, and (ii) local 73 anthropogenic activities, e.g. shipping. The three oceanic currents which supply the greatest water 74 volumes to the Arctic Ocean are the (i) West Spitsbergen Current i.e. the polar limb of the North 75 Atlantic circulation which carries warm water from the North Atlantic Current (9.5 Sverdrup, Sv $\left.76=10^{6} \mathrm{~m}^{3} \mathrm{~s}^{-1}\right)$, (ii) a cold ocean current that enters from the Pacific Ocean via the Bering Strait (1.5 $77 \mathrm{~Sv}$ ) and, (iii) a branch of the North Atlantic Current, which flows along the Siberian coastline (1.0 78 Sv), (Zarfl and Matthies 2010). These oceanic currents may also transport plastics to the Arctic 79 Ocean with the estimated plastic flux to this region ranging between 62000 to 105000 tons per 80 year (Zarfl and Matthies 2010). Models based on a particle-trajectory approach for studying the 81 fate of marine debris in the open ocean highlighted the northward transport of marine debris to 82 polar regions and the formation of a sixth so-called garbage patch in the Barents Sea (van Sebille 83 et al. 2012). Bio-transport is another long-range transport process via which plastics may enter 84 polar regions. Plastic ingestion was reported in Northern Fulmars (Fulmaris glacialis) and Thick85 billed Murres (Uria lomvia) in the Arctic (Mallory 2008; Provencher et al. 2012; Trevail et al. 86 2015). Some studies suggested that the seabirds had ingested plastics during their wintering in the

87 North Atlantic Ocean and had then transported the contaminants to the Arctic upon migration 88 (Mallory 2008; Provencher et al. 2012). Riverine discharge from Siberian (Ob, Yenisei and Lena) 89 and Canadian (Mackenzie) rivers are other potential sources of plastics to the Arctic. Obbard et al. 90 (2014), however, point out that the contribution of riverine discharge to plastic input in the Arctic 91 is projected to be low due to the fact that these rivers flow through sparsely populated watersheds. 92 Local anthropogenic activities are another source of plastics to the Arctic. Increased ship traffic 
93 due to shipping and tourism was found to be positively correlated with increased litter densities in

94 the Fram Strait (Bergmann and Klages 2012; Tekman et al. 2017).

96 The intense focus by scientists on the near-surface layer of the ocean for microplastics has been

97 due in part to the presumption that the majority of particles would be found in this region of the

98 water column given the inherent densities of individual synthetic polymers. Such a theorization

99 led to traditional techniques that involved nets, manta trawls as well as the seawater intake of

100 vessels that sampled only the upper few metres of the water column for microplastics. Yet, several

101 studies indicated that a mismatch existed between observed and expected plastic concentrations in

102 surface oceanic waters when estimated plastic production and projected inputs to the oceans were

103 considered (Cózar et al. 2014; Eriksen et al. 2014). It was therefore proposed that several

104 mechanisms potentially influenced the vertical distribution of microplastics within the water

105 column and led to their transport out of surface waters. Some of these mechanisms included (i)

106 incorporation into marine aggregates (Long et al. 2015), (ii) biofouling (Fazey and Ryan 2016),

107 (iii) incorporation into faecal matter (Cole et al. 2016) and, (iv) hydrodynamic factors such as wind

108 (Kukulka et al. 2012). Despite the theorization that surface waters are not the ultimate repository

109 for plastic debris in the marine environment (Cózar et al. 2014), few studies ventured beyond

110 traditional near-surface microplastic monitoring to investigate their vertical distribution in the

111 water column.

113 Microplastic pollution in the Arctic Ocean is an issue that warrants attention due to the potential

114 threats that these contaminants may pose to the inhabitants of this unique ecosystem. A practical

115 step towards addressing this issue and evaluating the extent of the problem involves assessing the 
116 abundance, distribution and composition of microplastics in Arctic waters. Whilst microplastic

117 monitoring in the marine environment has traditionally focused on surface waters, the reality is

118 that the vast majority of marine organisms inhabit sub-surface waters. Monitoring microplastics in

119 sub-surface waters is particularly relevant as it can also provide some insight into the whereabouts

120 of the 'missing plastic' from surface waters. To our knowledge, the present study sought for the

121 first time (i) to provide a spatial overview of microplastic abundance, distribution and composition

122 in the Polar Mixed Layer (PML) of the Arctic Central Basin (ACB) and, (ii) to determine whether

123 microplastics in the ACB were being transported out of surface waters by assessing their vertical

124 distribution in the water column.

125

$126 \quad 2.0$ Materials and Method

$127 \quad 2.1$ Study Area

128 The Arctic Ocean is comprised of a deep central basin surrounded by extensive continental shelves

129 (CAFF 2013). The bathymetry of the Arctic Ocean is such that the Lomonosov Ridge separates

130 the central basin into the Canadian (Amerasian) and Eurasian basins with the basins being further

131 sub-divided by the (i) Gakkel Ridge, into the Amudsen and Nansen basins and, (ii) Alpha Ridge,

132 into the Makarov and Canada basins (Jakobssen et al. 2004; Rudels 2015, Figure 1). A major

133 structuring element of the Arctic marine ecosystem is sea ice which floats on the surface layer

134 impeding surface mixing and influencing freshwater and heat fluxes (CAFF 2013). In the Arctic

135 Ocean, there is a distinct vertical stratification of the water column giving rise to three major water

136 layers (i) Polar Surface Water (PSW) which includes the Polar Mixed Layer (PML) and the

137 halocline, (ii) Atlantic Water and, (iii) deep and bottom waters (Rudels 2015, Figure 1). The PML

138 (approximately $50 \mathrm{~m}$ deep) is the uppermost surface layer of low salinity water formed as a result 
139 of sea ice melt and the influx of freshwater from riverine sources (Rudels et al. 1991; CAFF 2013;

140 Jakobsson et al. 2014). Beneath the PML is a halocline $(50-250 \mathrm{~m})$, characterised by a strong

141 salinity increase with depth and comprised of either Pacific waters or Atlantic waters with the

142 Pacific halocline being deeper than the Atlantic halocline (Rudels et al. 1991; Jakobsson et al.

143 2004). Below the halocline lies an intermediate water layer comprising of dense saline Atlantic

144 water. The deep and bottom waters also referred to as Arctic deep water ranges from a depth of 145 approximately $900 \mathrm{~m}$ and extend to the seafloor (Rudels et al. 1991; CAFF 2013).

$147 \quad$ 2.2 Sample Collection

148 Underway samples

149 This study was conducted onboard the Swedish icebreaker Oden during the Arctic Ocean 2016 150 expedition. The vessel departed Longyearbyen, Svalbard on August $8^{\text {th }} 2016$ and traversed 151 approximately 4943 nautical miles in the Arctic Ocean until its return on September $19^{\text {th }} 2016$ 152 (Figure 2). Sub-surface oceanic water pumped onboard the vessel via the bow water system was 153 sampled for microplastics according to Lusher et al. (2014). Sampling was conducted for a period 154 of approximately 6 weeks (9 August to 16 September 2016). Since each sample constituted the 155 filtration of approximately $2000 \mathrm{~L}$ of water, the total survey effort for this study was approximately $156116000 \mathrm{~L}$ of water (58 samples).

158 Seawater from a continuous intake located at the keel of the ship (depth $8.5 \mathrm{~m}$ ) was pumped 159 onboard the vessel using a rotary positive displacement pump (Universal II Series Pump, 160 Waukesha Cherry-Burrell) at a flow rate of $85 \mathrm{~L} / \mathrm{min}$ (at optimal capacity) and transported to the 161 laboratory via stainless steel pipes. Prior to reaching the laboratory, the seawater passed through a 
162 stainless steel primary filter (pore size $2.5 \mathrm{~mm}$ ) which was beyond the control of the investigator.

163 The discharge of grey water in relation to the seawater intake was not an issue since the seawater

164 intake was located towards the front of the vessel whilst grey water was discharged mid-vessel. In

165 the laboratory, seawater from the vessel's bow water system was allowed to flow through a covered

166 stainless steel sieve $(250 \mu \mathrm{m})$ by means of a connection hose fitted into the wooden sieve cover.

167 For the duration of the sampling, the stainless steel sieve was supported in a wooden stand. Based 168 on Lusher et al. (2014), approximately 2000 L of water was filtered for each sample. The length

169 of time taken for the filtration of the specified volume of water was determined by calculation of

170 the flow rate of the seawater. A flow meter, attached at a point prior to the entry of the water into

171 the sieve, was also used to verify the volume of water filtered. Once the specified volume of water

172 was filtered, the sieve was removed and Milli-Q water was used to wash retained material from

173 the sieve into a clean container. The collected material was then filtered under vacuum onto glass

174 microfiber paper $(\mathrm{GF} / \mathrm{C})$; Whatman: $47 \mathrm{~mm}$, pore size: $1.2 \mu \mathrm{m}$, using a Buchner funnel and a 175 vacuum flask (Lusher et al. 2014). Each filter paper was then placed into a clean plastic petri dish, 176 covered and stored in a freezer $\left(-20^{\circ} \mathrm{C}\right)$ until returned to the laboratory. At the start and at the end 177 of each sample, positioning data were collected. Data for various environmental variables were 178 obtained from the vessel's (i) thermosalinometer (water temperature, salinity) and (ii) weather 179 station (wind speed and direction).

\section{CTD samples}

182 A rosette water sampler containing 24 Niskin bottles coupled to a Sea-Bird SBE 911 conductivity183 temperature-depth (CTD) sensor suite (hereafter referred to as CTD) was used to collect sub184 surface water samples and hydrographic data at 9 sampling locations in the Arctic Ocean. Upon 
185 deployment from the vessel, the CTD entered the water and was allowed to descend to the bottom

186 layer. During the descent, Niskin bottles were open with water flowing through them. It was during

187 the up-cast that multiple Niskin bottles were closed at specific depths in order to facilitate the 188 collection of a specified volume of water. A total of 48 water samples were retrieved during the 9 189 CTD casts to sample for microplastics. At 7 of the CTD casts, 6 water depths were sampled with $19048 \mathrm{~L}$ of water collected at each depth i.e. 4 Niskin bottles (12 L) per depth. At 2 CTD casts, 3 water 191 depths were sampled with $21 \mathrm{~L}$ of water collected at each depth i.e. 3 Niskin bottles (7 L) per 192 depth. At a particular sampling location, the overall goal was to collect samples in the near-surface, 193 mid-water and bottom layers within the water column thereby reflecting the main water masses. 194 As such, exact sampling depths were determined by the information provided by the salinity and 195 temperature sensors on each downcast. The deepest samples at each CTD cast were collected at 196 least $10 \mathrm{~m}$ above the seafloor at a given location. Following each CTD cast, Niskin bottle taps 197 were rinsed with Milli-Q water and a clean hose was attached. Water from bottles closed at the 198 same depth was passed through the same stainless steel sieve $(250 \mu \mathrm{m})$ held in a covered wooden 199 stand. Once water from all bottles at a specific depth had been filtered, the sieve was removed and 200 Milli-Q water was used to wash retained material from the sieve into a clean container. The 201 collected material was filtered under vacuum onto glass microfiber paper (GF/C); Whatman: 47 $202 \mathrm{~mm}$, pore size: $1.2 \mu \mathrm{m}$, using a Buchner funnel and a vacuum flask. Each filter paper was then 203 folded and placed into an aluminium foil packet and stored in a freezer $\left(-20^{\circ} \mathrm{C}\right)$ until returned to 204 the laboratory.

205

206

\subsection{Method Validation and Contamination Prevention}


207 For the underway samples, potential contamination during sample processing was evaluated by (i)

208 leaving clean plastic petri dishes with filter paper exposed to the air during vacuum filtration, and

209 (ii) passing an aliquot $(250 \mathrm{~mL})$ of Milli-Q water through clean GF/C filter paper under vacuum.

210 For the CTD samples, potential contamination was assessed by filling a clean Niskin bottle with

211 Milli-Q water and subjecting it to the exact process a sample underwent. Measures taken to prevent

212 contamination in the laboratory included (i) wearing lab coats (cotton/polyester blend), cotton

213 clothing and gloves (nitrile) during sample processing, (ii) placing a wooden cover over the

214 stainless steel sieve during filtration to prevent airborne contamination, and (iii) washing all

215 containers used during sample processing with Milli-Q water before reuse.

\section{$217 \quad 2.4$ Laboratory analyses}

218 Filter papers were removed from the freezer, left to dry and then visually examined under a 219 dissecting microscope (Olympus SZX10) equipped with a polariser and camera (Q Imaging Retiga 220 2000R). Potential microplastics were isolated and processed (photographed and length 221 measurements taken) prior to transferring to a clean filter paper in a labelled petri dish (Kanhai et 222 al. 2017). All potential microplastics were analysed by Fourier transform infrared (FT-IR) 223 spectroscopy on a Thermo Scientific Nicolet iN10 FT-IR spectrometer. The instrument was 224 equipped with a potassium bromide $(\mathrm{KBr})$ beamsplitter and an internal mercury cadmium telluride 225 (MCT) detector which was cooled with liquid nitrogen. Microscope-reflectance sampling was 226 performed and spectra were recorded as the average of 256 scans in the spectral wave number 227 range of $4000-675 \mathrm{~cm}^{-1}$ at a resolution of $4 \mathrm{~cm}^{-1}$. Thermo Scientific's OMNIC Picta Version 9 228 spectroscopy software was used for processing and evaluating all spectra. Prior to analysing each 229 sample, background scans were performed and sample spectra were automatically corrected. Each 
230 sample spectrum was compared with those of known standard polymers in the (i) Hummel

231 Polymer Sample library, (ii) Polymer Laminate Films library, and (iii) Wizard library. Values of

232 between 0 and $100 \%$ were produced for each match between sample and reference spectra with

233 the highest percentage representing the closest match. Particles for which there was uncertainty

234 regarding the identity of the polymer (specifically fragments and some fibres) were subjected to

235 further FT-IR spectroscopy on a Bruker Vertex 70 Infrared Spectrometer coupled to a Hyperion

2361000 microscope (Kanhai et al. 2017). Samples which produced spectra with a match < $60 \%$ were

237 automatically rejected while those with a match of $>70 \%$ were automatically accepted. All spectra

238 with matches $>60 \%$ were individually examined to ensure that there was clear evidence of peaks

239 from the sample corresponding to known peaks of standard polymers and that instances of the

240 misidentification of natural and semi-synthetic polymers was reduced (Comneau-Stancu et al.

241 2017).

242

$243 \quad 2.5$. Statistical analyses

244 All statistical analyses were performed using R version 3.2.3 (R Core Team 2015). Descriptive 245 statistics, histograms and box plots were generated and tests of normality (Supplementary Tables 2461 and 2) were conducted on all data to determine whether parametric or non-parametric statistical 247 analyses were appropriate. Correlation analyses were performed between individual 248 environmental variables and microplastic abundance for both underway and CTD samples. A 249 generalized additive model (GAM) was developed using the underway data and a generalized 250 linear mixed model (GLMM) was developed using the CTD data to determine which 251 environmental variables had an effect on microplastic abundance. 


\section{3. Results}

\section{3.1. Quality Control}

255 In conjunction with the collection of samples via the underway system of the vessel, a total of 24 256 blanks (air contamination-12, method-12) were run (Supplementary Table 3). No synthetic 257 polymers were found in the method blanks. However, a single synthetic fibre (blue, polyethylene 258 terephthalate, $0.438 \mathrm{~mm}$ ) was found in the last air contamination blank. For 6 of the 9 CTD casts, 259 at least one method blank was run (Supplementary Table 4). Between 0 and 3 synthetic fibres were 260 found in each of the method blanks. The synthetic fibres that were found included polyethylene 261 terephthalate $(n=8)$, polyacrylonitrile $(n=1)$ and polyvinyl chloride $(n=1)$.

\subsection{Overview of findings}

\section{Underway samples}

265 A total of 303 particles were isolated from the underway samples and analysed by FT-IR 266 spectroscopy. Of these, 46 particles were excluded because of uncertainty regarding their identity $267(<60 \%$ match to reference spectra) and in the minority of cases $(n=6)$ due to their length $(<250$ $268 \mu \mathrm{m})$. Of the remaining particles $(\mathrm{n}=257), 14$ were macro-particles (i.e. $>5 \mathrm{~mm}$ in length) and 243

269 were micro-particles $(<5 \mathrm{~mm}$ in length). Of the macro-particles, 11 were confirmed as 270 macroplastics having the following polymer types: polyethylene terephthalate (4), polyamide 271 blend (4) and polyacrylonitrile (3). Of the 243 micro-particles, 110 were natural (cellulosic), 16 272 were semi-synthetic (cellulose-based e.g. rayon) and 117 were synthetic. All further analyses and 273 discussions focus on the 117 confirmed microplastics. 
275 The majority (94\%) of microplastics were fibres and $6 \%$ were fragments. In terms of colour, the 276 most prevalent were blue (49\%) and transparent (25\%) (Figure 3a). Approximately $62 \%$ of the

277 microplastics occurred in the larger size classes of $1.0-2.0 \mathrm{~mm}$ and $2.0-5.0 \mathrm{~mm}$ (Figure 4a).

278 Microplastic polymer types included polyester $(\mathrm{n}=88)$, blends $(\mathrm{n}=11)$, polyacrylonitrile $(\mathrm{n}=8)$,

279 polyamide $(n=5)$ and polyvinyl chloride $(n=5)$, (Figure 5a). The overall category of 'polyester'

280 included both polyethylene terephthalate (PET) and other polyesters while blends included either 281 polyamide blends or polyester blends.

282

283 CTD samples

284 A total of 157 particles were isolated from the CTD samples and analysed by FT-IR spectroscopy. 285 Of these, 14 were excluded for the reasons mentioned above for the underway samples. Of the 286 remaining particles, 2 were categorised as macroplastics $(>5 \mathrm{~mm})$ and included PET and 287 polyacrylonitrile. Of the 141 micro-particles $(<5 \mathrm{~mm}), 39$ were natural (cellulosic), 8 were semi288 synthetic (cellulose-based e.g. rayon) and 94 were synthetic. All further analyses and discussions 289 focus on the 94 confirmed microplastics.

291 Overall, the characteristics of the microplastics isolated from CTD samples were similar to those 292 from the underway samples in that (i) the majority (96\%) of microplastics were fibres and $4 \%$ 293 were fragments, (ii) the most prevalent colours were blue (46\%) and transparent (22\%) (Figure 294 3b), (iii) the majority (64\%) of microplastics were in the larger size classes of $1.0-2.0 \mathrm{~mm}$ and $2952.0-5.0 \mathrm{~mm}$ (Figure 4b), and (iv) microplastic polymer types included polyester $(\mathrm{n}=74)$, blends $296(n=12)$, polyacrylonitrile $(n=6)$, polyamide $(n=1)$ and polyvinyl chloride $(n=1)$, (Figure 5b). 
297 The overall category of polyester included both polyethylene terephthalate (PET) and polyester

298 while blends included only polyamide blends.

\subsection{Microplastic abundance and distribution in the Arctic Ocean}

301

Based on the underway samples (collection depth $8.5 \mathrm{~m}$ ), microplastic abundance in sub-surface waters in the Arctic Ocean ranged between $0-7.5$ particles $\mathrm{m}^{-3}$ with a median of 0.7 particles $\mathrm{m}^{-}$ 3 (interquartile range $0.4-1.0$ ), (Figure 2, Supplementary Table 5). For the majority of the sampling sites, microplastic abundance ranged between $0-1.0$ particles $\mathrm{m}^{-3}$. However, at a few sites, microplastic abundances were between $2-2.5$ particles $\mathrm{m}^{-3}$ and at two sites it was at 5 and 7.5 particles $\mathrm{m}^{-3}$ respectively. Based on the CTD samples (collection depths between $8-4369 \mathrm{~m}$ ), microplastic abundance in sub-surface waters in the Arctic Ocean ranged between $0-375$ particles $\mathrm{m}^{-3}$ with a median of 20.8 particles $\mathrm{m}^{-3}$ (interquartile range $20.8-62.5$ ) (Figures 2 and 5, Supplementary Table 6). With the exception of CTD cast 4 , the CTD casts $(1-3)$ nearer the periphery of the Arctic Central Basin (ACB), i.e. in the Nansen Basin (Yermak Plateau), reflected a comparatively higher abundance of microplastics in the water column than other CTD casts within the ACB (Figures 2, 6). It must be noted however that CTD casts $1-3$ sampled the upper $850 \mathrm{~m}$ of the water column and as such would have sampled particles from the Polar Mixed Layer (PML), Atlantic halocline and Atlantic water (Figures 1, 6). This is in contrast to the other CTD casts which sampled a much more extensive vertical range throughout the water column by including deep bottom water in excess of $1000 \mathrm{~m}$ depth. Overall, there was no statistically significant correlation between microplastic abundance and depth (Spearman's rank correlation, rho $=0.06$, p-value $=0.7)$. However, upon examination of individual CTD casts, it is apparent that microplastic abundance was not uniform at various depths in the water column and that there were 
320 certain depths that reflected higher microplastic abundances (Figure 6). Additionally, microplastic

321 abundance (particles $\mathrm{m}^{-3}$ ) in the different water masses of the ACB was as follows: Polar Mixed

322 Layer $(0-375)>$ Deep and bottom waters $(0-104)>$ Atlantic water $(0-95)>$ Halocline i.e.

323 Atlantic or Pacific $(0-83)$, (Table 1).

324

325

\subsection{Association between environmental variables and microplastic abundance in samples}

326 Correlation analyses were conducted to determine whether there was any association between

327 environmental variables and microplastic abundance in the samples. For both the underway and

328 CTD samples, there was no statistically significant correlation between microplastic abundance

329 and any of the ancillary environmental variables of temperature, salinity, wind direction, wind

330 speed, depth and density (Supplementary Tables 1 and 2). Specifically, there was no statistically

331 significant correlation between microplastic abundance at depth (Supplementary Table 2).

332 However, for the underway samples, there was a statistically significant weak negative correlation

333 between microplastic abundance and latitude (Spearman's rank correlation, rho $=-0.286$, p-value

$334=0.03)$.

335

336 Using the underway data, a Generalized Additive Model (GAM) was developed to further

337 determine whether environmental variables influenced microplastic count in the underway

338 samples. In this model, the response variable was microplastic count (number of microplastics per

339 sample) and initial explanatory variables included location (latitude, longitude), physico-chemical

340 properties associated with sub-surface waters (temperature, salinity) and weather data (wind

341 direction, wind speed). In the model, the Poisson family distribution of error terms was specified

342 with a log link function since microplastic abundance data were count data. The output of the 
343 initial model was examined and based on this non-parametric smoothers were accordingly applied

344 to the explanatory variables. A scale invariant tensor product smooth (te) was applied to latitude

345 and longitude while a cubic regression spline $(\mathrm{bs}=\mathrm{cr}$ ) was applied to all other variables except

346 wind direction to which no smoother was applied (based on initial model plots). Non-significant

347 explanatory variables (as evidenced by their p-values) were eliminated in a stepwise manner until

348 a GAM with the lowest Akaike Information Criterion (AIC) score and the fewest explanatory

349 variables was obtained. The final GAM $(\mathrm{R}-\mathrm{sq}=0.396)$ was as shown below:

350

351 Microplastic count $\sim$ te(latitude, longitude $)+s($ temperature, $b r=$ "cr" $)+s($ wind speed, $b s=$ 352 “cr")

353

354 All of the explanatory variables that were present in the final model (shown in bold) were found 355 to have a significant influence on microplastic count in water samples from the Arctic Ocean (wind 356 speed, $\mathrm{p}$-value $=0.0006$, latitude, longitude, $\mathrm{p}$-value $=0.0007$, temperature, $\mathrm{p}$-value $=0.0483$ )

358 A generalized linear mixed model (GLMM) was developed using the CTD data to determine the 359 influence of environmental variables on microplastic count in the CTD samples. In this model, the 360 response variable was microplastic count (number of microplastics per sample) and initial 361 explanatory variables included location (latitude, longitude), physicochemical properties 362 associated with sub-surface waters (temperature, salinity), depth at which water was sampled and 363 ctd number. All the explanatory variables were included in the model as fixed effects, with the 364 exception of ctd number which was included as a random effect. In the model, the Poisson family 365 distribution of error terms was specified with a log link function since microplastic abundance data 
were count data. Based on the preliminary finding that there was a statistically significant

367 correlation between depth and salinity (Spearman's rank correlation, rho $=0.852$, $\mathrm{p}$-value $=$

368 8.156e-13), temperature and salinity (Spearman's rank correlation, rho $=0.506$, $\mathrm{p}$-value $=0.00074$ )

369 and depth and density (Spearman's rank correlation, rho $=0.973$, p-value $=<2.2$ e-16),

370 interactions between these variables (denoted by ':') were included in the initial model. Non-

371 significant explanatory variables (as evidenced by their p-values) were eliminated in a stepwise

372 manner until a model with the lowest Akaike Information Criterion (AIC) score and the fewest

373 explanatory variables was obtained. The significance of the random effect (ctd number) in the final

374 model was verified by using analysis of variance (ANOVA) to compare the full final model to a

375 reduced model (random effect deleted). The model with the random effect was shown to be

376 significantly different (ANOVA, $\mathrm{p}$-value $=0.0008, \Delta \mathrm{AIC}=9.19)$ from the model without the

377 random effect. The model with the lower AIC score (AIC $=190.59)$ was retained as the final mixed

378 effects model as shown below:

379

380

Microplastic count $\sim$ latitude + temperature:salinity $+(1 \mid c t d)$

381

382 Latitude $(\mathrm{p}$-value $=0.0198)$ and the physicochemical parameters of temperature and salinity $(\mathrm{p}$ -

383 value $=7.46 \mathrm{e}-05)$, as shown in bold, were the explanatory variables that were found to have a 384 significant influence on microplastic count in the CTD samples.

$386 \quad 4.0$ Discussion

387 The discovery of microplastics in virtually every environmental phase (sea ice, water, sediments, 388 biota) of the Arctic and Southern Oceans has revealed that polar oceans, though remote, are not 
immune to the entry of plastic contaminants to their ecosystems (Bergmann and Klages 2012; Obbard et al. 2014; Lusher et al. 2015; Amélineau et al. 2016; Bergmann et al. 2016; Bergmann et al. 2017a; Bergmann et al. 2017b; Cincinelli et al. 2017; Cózar et al. 2017; Isobe et al. 2017; Tekman et al. 2017; Waller et al. 2017). The present study expands the knowledge base about plastics in the Arctic by providing evidence for the existence of microplastics in the Polar Mixed Layer (PML) as well as some insight into the vertical distribution of microplastics in the Arctic Central Basin (ACB). This region of the Arctic, though of low productivity, has been recognised as an Ecologically/Biologically Significant Marine Area (EBSA) due to its uniqueness/rarity, provision of a critical habitat and ability to support specialised biota (CAFF 2017). There is cause for concern about microplastics in Arctic waters since laboratory studies have shown that these contaminants may (i) hinder algal photosynthesis/growth (Bhattacharya et al. 2010; Besseling et al. 2014), (ii) reduce feeding and energy reserves of lugworms (Besseling et al. 2013; Wright et al. 2013), (iii) reduce filtering activity and decrease lysosomal membrane stability in mussels (Von Moos et al. 2012; Wegner et al. 2012), (iv) reduce feeding and reproductive output in copepods (Cole et al. 2015) and, (v) cause liver stress, negatively impact upon cholinergic neurotransmission and lead to endocrine disruption in fish (Oliveira et al. 2013; Rochman et al. 2013; Rochman et al. 2014). It must be pointed out, however, that some laboratory experiments which reported negative effects of microplastics on marine organisms used microplastic concentrations of 42 to 10000 particles/mL or 42 million to 10 billion particles $\mathrm{m}^{-3}$ (Phuong et al. 2016). In context, microplastic abundance in the ACB as reported by the present study ranged from $0-7.5$ particles $\mathrm{m}^{-3}$ (based on underway sampling) and $0-375$ particles $\mathrm{m}^{-3}$ (based on CTD sampling). Although the ecological impact of microplastics upon the Arctic ecosystem presently remains unknown, it is plausible that these contaminants could pose a threat to its inhabitants. 
413 The present study showed for the first time the pervasiveness of microplastics throughout the water

414 column of the Arctic Central Basin. Between depths of $8-4400 \mathrm{~m}$, microplastic abundance in the 415 ACB ranged between $0-375$ particles $\mathrm{m}^{-3}$ (based on CTD sampling). Such findings provide 416 evidence that in natural conditions microplastics are being vertically transported out of surface 417 waters. These findings also give some indication as to the whereabouts of the 'missing plastic' 418 from oceanic surface waters (Cózar et al. 2014; Eriksen et al. 2014). Recently, Courtene-Jones et 419 al. (2017) also reported on microplastic abundance (70.8 particles $\left.\mathrm{m}^{-3}\right)$ in deep oceanic waters 420 (2227 $\mathrm{m}$ at the Rockall Trough, North East Atlantic Ocean) and similarly suggested the possibility 421 of vertical re-distribution of microplastics within the water column. Although it remains unclear 422 as to which mechanisms are specifically operating in the ACB to influence the vertical transport 423 of particles, previous studies have provided several possibilities. Specifically, some laboratory 424 experiments showed that aggregates of algae species (Chaetoceros neogracile, Rhodomonas 425 salina) were capable of incorporating and concentrating microplastics and that the microplastics 426 impacted the sinking rates of the aggregates (Long et al. 2015). In the Arctic Ocean, it is certainly 427 plausible that marine aggregates may be playing a role in the vertical transport of microplastics 428 due to the existence of phytoplankton in the ACB (CAFF 2017) and the fact that transparent 429 exopolymer particles (TEPs); which are excreted by algae and are important components of marine 430 aggregates, have been reported in sub-surface waters as far north as the Fram Strait (Engel et al. 431 2017). Biofouling is another possibility as field studies have shown that plastic particles exposed 432 to natural conditions became sufficiently fouled, had their average material density affected 433 leading them to sink (Fazey and Ryan 2016). The incorporation of microplastics into faecal matter 434 is another means by which microplastics may be vertically transported out of surface waters given 
435 that laboratory experiments have shown that zooplankton may egest microplastics within densely

436 packed faecal pellets which in natural conditions would sink or in some cases be eaten by other

437 biota (Cole et al. 2016).

439 Sea ice is an integral component of the Arctic Ocean's ecosystem and as such possibly exerts an 440 influence on microplastic abundance in sub-surface waters. Sea ice floating on the surface of the 441 water column in the Arctic Ocean can potentially act as (i) a source of microplastics upon melting,

442 (ii) a physical barrier to wind and as such reduce vertical mixing of surface waters and, (iii) a 443 physical barrier to influx of polluted surface waters. Based on the analysis of sub-sections of four 444 ice cores, sea ice in the Arctic Ocean was reported to contain orders of magnitude more 445 microplastic than contaminated oceanic waters suggesting that sea ice potentially acts as both a 446 sink and a source of microplastics (Obbard et al. 2014). Apart from Obbard et al. (2014) no data 447 exists in the published literature regarding either the spatial or vertical distribution of microplastics 448 in sea ice from the Arctic Ocean. In the upper water column, the absence of sea ice cover means 449 that wind stress can generate turbulence and lead to vertical mixing of buoyant plastic debris 450 (Kukulka et al. 2012). More recently, Cózar et al. (2017) suggested that sea ice can also act as a 451 physical barrier preventing the surface advance of polluted Atlantic water into the Arctic Ocean. 452 The present study highlighted that the Polar Mixed Layer (PML) of the ACB reflected the highest 453 overall microplastic abundance (particles $\left.\mathrm{m}^{-3}\right)$ : Polar Mixed Layer $(0$ - 375) > Deep and bottom 454 waters $(0-104)>$ Atlantic water $(0-95)>$ Halocline i.e. Atlantic or Pacific $(0-83)$. As previously 455 mentioned, the PML is the uppermost surface layer of low salinity water (approximately $50 \mathrm{~m}$ 456 deep) formed as a result of sea ice melt and the influx of freshwater from riverine sources (Rudels 457 et al. 1991; CAFF 2013). It is possible that one of the reasons that the highest microplastic 
458 abundances were recorded in this layer is due to its proximity to microplastic sources such as

459 melting sea ice as well as sea-going vessels (especially if they are releasing wastewater to the

460 environment). Furthermore, in the present study, the highest microplastic abundances were

461 reported nearer to the periphery of the Arctic Central Basin (ACB), i.e. in waters north of Svalbard.

462 It is possible that the lack of permanent sea ice cover in this region of the Arctic allows incoming

463 Atlantic water to have a greater influence on near surface waters thereby resulting in higher 464 microplastic abundances. A recent circumpolar expedition of the Arctic Ocean similarly reported 465 that the north eastern Atlantic sector of the Arctic was a hotspot of plastic debris due to the 466 influence of incoming Atlantic water (Cózar et al. 2017).

468 The present study showed that there was a predominance of fibrous microplastics (> 90\%) in sub469 surface waters of the ACB. This dominance of fibres in sub-surface waters was similarly reported 470 in (i) the north east Pacific Ocean (75\%), (ii) the north east Atlantic Ocean (96\%), (iii) 471 south/southwest of Svalbard (95\%), and (iv) the Atlantic Ocean (96 \%) (Desforges et al. 2014; 472 Lusher et al. 2014; Lusher et al. 2015; Kanhai et al. 2017). Fibrous microplastics in the marine 473 environment most likely originate from textile materials and fishing gear (Andrady 2017). Studies 474 have indicated that washing clothes may lead to the release of fibrous materials in the order of > 4751900 fibres per wash or as much as 700000 fibres per $6 \mathrm{~kg}$ load of acrylic fabric (Browne et al. 476 2011; Napper and Thompson 2016). A recent study in the Ross Sea revealed that the highest 477 concentration of fibrous microplastics $(54 \%)$ was found close to the effluent of a sewage treatment 478 plant at the scientific Mario Zucchelli Station, Antarctica (Cincinelli et al. 2017). Fibrous 479 microplastics may enter the Arctic Ocean through a combination of long range transport processes 480 (e.g. via oceanic currents, riverine input) or more in-situ activities such as the release of wastewater 
481 from vessels operating in the region. Another mechanism which was recently suggested as being 482 responsible for plastic fibres in Arctic sea ice was atmospheric transport (Cózar et al. 2017). This 483 is certainly plausible as there have been reports of the atmospheric fallout of synthetic polymers 484 in both urban and sub-urban environments in France (Dris et al. 2016). It must be highlighted that 485 while fibrous microplastics seem to be dominant in certain sub-surface waters, other studies 486 conducted in surface Arctic waters reported a predominance of filaments (97\%) and fragments 487 (73 \%), (Amélineau et al. 2016; Cózar et al. 2017).

Analytical techniques such as FT-IR and Raman spectroscopy are a central component of microplastic studies which aim to provide unambiguous identification of synthetic polymers in 491 environmental samples. Omission of this critical step is likely to be a key contributor to an 492 overestimation of microplastic abundances due to the inclusion of non-synthetic polymers in 493 microplastic counts. In the present study, for example, only a percentage (underway - $48 \%$, CTD $494-67 \%$ ) of the particles were confirmed as synthetic polymers with the remainder being a 495 combination of natural and semi-synthetic polymers. Of the synthetic polymers in the present 496 study, the most abundant (underway - $74 \%$, CTD - $78 \%$ ) was polyethylene terephthalate (PET). 497 A member of the polyester family, PET is one of the five major types of commodity plastics 498 commonly found in the marine environment (Andrady 2011; Andrady 2017). As a thermoplastic, 499 PET is often used in manufacturing beverage containers and packaging materials and its fibres are 500 used in clothing. Overall, this finding of a high prevalence of polyesters in sub-surface waters of 501 the Arctic Central Basin was also corroborated by those of other Arctic studies which reported that 502 polyester was the most prevalent synthetic polymer in waters south/southwest of Svalbard (15\%), 503 in waters of the east Greenland Sea (53\%), and in sea ice (21\%), (Obbard et al. 2014; Lusher et 

included polyacrylonitrile, polyamide and polyvinyl chloride. Of note is the fact that the majority of synthetic polymers in the present study had densities greater than that of seawater (Andrady

507 2017). Even though investigators are able to generate information regarding the identity of 508 polymers in environmental samples, definitive statements cannot be made about the origin of the 509 plastics. Based on the identity and type of synthetic polymers found in sub-surface Arctic waters, 510 it is likely that they originated from textiles, fishing gear, beverage containers and packaging 511 materials (Andrady 2011; Andrady 2017).

513 Within the water column, the distribution of microplastics is in a state of flux due to the influence 514 of multiple factors. The development of models based on simultaneously acquired environmental 515 and microplastic data is immensely useful in this respect as they can provide some discernment 516 regarding the variables influencing measures of microplastic abundances in the marine 517 environment. In the present study, the utilisation of a generalized additive model (GAM) and a 518 generalized linear mixed effects model (GLMM) was particularly relevant due to the ability of 519 both models to handle non-normal data and in the case of the GLMM to differentiate between 520 fixed and random effects. Visual inspection of microplastic abundances in sub-surface waters 521 (Figure 2) revealed that the highest microplastic abundances were located to some extent towards 522 the periphery of the Arctic Central Basin (ACB). Bearing this in mind, it was presumed that the 523 'location' of sampling could have influenced the number of microplastics that were found in the 524 samples. Cózar et al. (2017) also noted this spatial heterogeneity in the distribution of plastics in 525 the Arctic. For these reasons, latitude and longitude were included as a proxy of location in the 526 models. In the GAM, both variables were included using a smoother and therefore it was not 
527 assumed that latitude and longitude had a linear effect on microplastic count. Furthermore, during

528 the period of sampling (August/September 2016), the Arctic Central Basin (ACB) was not

529 completely covered by sea ice. Since the vessel traversed areas of open water, wind was included

530 in the model as it could have influenced microplastic abundance at specific sampling sites. Both

531 models suggested that location, oceanographic (temperature, salinity) and atmospheric variables

532 (wind) had a significant influence on microplastic counts in samples of water from the Arctic

533 Ocean. The findings of the present study must be taken in the context of the number of samples

534 used in the generation of the GAM $(n=58)$. Models that are based on a low number of samples

535 are weak e.g. standard errors are inflated, etc. However, such models allow us to delve a bit deeper

536 into the factors influencing measurements of microplastic abundance in the Arctic Ocean. Findings

537 of the present study were also corroborated by previous studies which indicated that water 538 temperature, salinity and wind also had a significant effect on microplastic abundance (Lusher et

539 al. 2014; Lusher et al. 2015; Kanhai et al. 2017).

540

541 Comparative assessments between oceanic basins are critical in providing an indication of the 542 extent of microplastic pollution in the marine environment. A major challenge, which demands 543 caution when drawing conclusions from such comparisons, is the lack of standardization of 544 microplastic sampling methods (depth of collection, mesh size of net/sieve, etc). Microplastic 545 abundances in the present study were not normally distributed and therefore the median was 546 reported as it is the most relevant measure of central tendency for such data. However, in order to 547 enable comparability with other published studies, which generally did not report median 548 microplastic abundances nor made statements about the normality of their data, the mean was also 549 reported in Supplementary Table 7. In the present study, sub-surface waters (depth $8.5 \mathrm{~m}$ ) in the 
550 Arctic Central Basin (ACB), sampled via the bow water system, had a mean microplastic 551 abundance of $0.97 \pm 1.20$ particles $\mathrm{m}^{-3}$. In comparison to other studies that employed similar 552 methods (i.e. the underway system of vessels) to sample sub-surface waters, microplastic 553 abundance in the ACB was lower than values reported (i) in the north eastern Pacific Ocean (279 $554 \pm 178$ particles $\left.\mathrm{m}^{-3}\right)$, (ii) in the North Atlantic Ocean $\left(13-501\right.$ particles $\left.\mathrm{m}^{-3}\right)$, (iii) off Svalbard $555\left(2.68 \pm 2.95\right.$ particles $\left.\mathrm{m}^{-3}\right)$, (iv) in the north east Atlantic Ocean $\left(2.46 \pm 2.43\right.$ particles $\left.\mathrm{m}^{-3}\right)$, and (v) 556 in the Atlantic Ocean (1.15 \pm 1.45 particles $\mathrm{m}^{-3}$ ), (Desforges et al. 2014; Lusher et al. 2014; Enders 557 et al. 2015; Lusher et al. 2015; Kanhai et al. 2017, Supplementary Table 7). The only oceanic basin 558 for which there were reports of lower microplastic abundances in sub-surface waters was the Ross 559 Sea $\left(0.17 \pm 0.34\right.$ particles $\left.\mathrm{m}^{-3}\right)$, (Cincinelli et al. 2017; Supplementary Table 7). Although the 560 methods used to sample sub-surface waters for microplastics in the above mentioned studies were 561 similar, the fact remains that the variation of several factors e.g. mesh size of sieve $(1-300 \mu \mathrm{m})$, 562 sampling depth $(3-11 \mathrm{~m})$, etc., amongst the studies could have impacted the reported microplastic 563 abundances. In terms of assessing the vertical distribution of microplastics in the marine 564 environment, Bagaev et al. (2017) was the only other published study which utilised a similar 565 sampling method (Niskin bottles) in the Baltic Sea. Being cognisant of the fact that no 566 confirmatory analytical techniques or blanks were used by Bagaev et al. (2017), microplastic 567 abundance at multiple depths in sub-surface waters of the Arctic Ocean (mean: $46 \pm 62$ particles $568 \mathrm{~m}^{-3}$; range: $0-375$ particles $\mathrm{m}^{-3}$; depths sampled: $8-4400 \mathrm{~m}$ ) was lower than reported for the 569 Baltic Sea (mean: $310 \pm 520$ particles $\mathrm{m}^{-3} ; 70-2600$ particles $\mathrm{m}^{-3}$; depths sampled: $1-218 \mathrm{~m}$ ). 570 Similar to the findings of the present study whereby the highest microplastic abundances were 571 found in the uppermost water layer i.e. the PML, Bagaev et al. (2017) reported that near- surface 572 and near-bottom water layers in the Baltic Sea had higher fibre concentrations than intermediate 
573 layers and that this was possibly due to greater turbulence and density stratification in those layers.

574 Of note is the fact that microplastic abundance in deep waters of the ACB $\left(0-104\right.$ particles $\mathrm{m}^{-3}$,

575 depths $1000-4400 \mathrm{~m}$, sieve $250 \mu \mathrm{m}$ ) was similar to those reported for deep waters at the Rockall

576 Trough, North East Atlantic Ocean (70.8 particles $\mathrm{m}^{-3}$, depth $2227 \mathrm{~m}$, sieve $\left.80 \mu \mathrm{m}\right)$, (Courtene-

577 Jones et al. 2017). Overall, it must be acknowledged that an underestimation of microplastic

578 abundance in the Arctic Central Basin (ACB) could have occurred in the present study as the mesh

579 size of the sieve was only $250 \mu \mathrm{m}$ leading to an exclusion of smaller sized particles. Nevertheless,

580 the Arctic's remote geographic location away from major population centres, its low population

581 in its surrounding continental shelves and relatively low in-situ anthropogenic activities (e.g.

582 shipping) are all factors which may explain the lower microplastic abundances in sub-surface

583 waters within the Arctic Central Basin (ACB). From an oceanographic perspective, the reduced

584 contribution of Atlantic water in its upper water layers due to the dominance of the polar mixed

585 layer is another possible explanation for lower microplastic abundances in the Arctic in

586 comparison to other oceanic basins. Presumably more polluted, Atlantic water which originates

587 from the more densely populated southern latitudes has its surface advance into the Arctic Ocean

588 hindered due to freshwater released from melting ice and other physical barriers such as the sea

589 ice itself and the Novaya Zemlya islands (Cózar et al. 2017). However, a plausible future scenario

590 for the Arctic in the context of a changing climate is that microplastic abundance in near-surface

591 layers of the Arctic Ocean may increase upon melting of contaminated sea ice and opening up of

592 shipping lanes due to a decrease in sea ice extent (Obbard et al. 2014; Cózar et al. 2017).

593

594 Of interest is the fact that the present study managed to sample microplastics in sub-surface waters

595 at approximately $8.5 \mathrm{~m}$ depth by two independent methods i.e. by the bow water system of the 
vessel (underway sampling) and the rosette water sampler (CTD sampling). CTD samples $(\mathrm{n}=9)$

597 retrieved from an average depth of $8.5 \mathrm{~m}$ indicated that microplastic abundance in the ACB ranged

598 between $0-148$ particles $\mathrm{m}^{-3}$, with a median of 20.8 particles $\mathrm{m}^{3}$. By comparison, samples

599 collected via the underway system $(\mathrm{n}=58)$ at $8.5 \mathrm{~m}$ indicated that microplastic abundance in the

600 ACB ranged between $0-7.5$ particles $\mathrm{m}^{3}$, with a median of 0.7 particles $\mathrm{m}^{3}$. Although both

601 methods sampled water at an average depth of $8.5 \mathrm{~m}$, calculated microplastic abundances from

602 both methods are not directly comparable due to the differences associated with the methods.

603 Whereas underway sampling involved filtration of a greater volume of water (approximately 2000

604 L) over a longer distance and a longer sampling time (> 2 hours), the CTD sampling involved the

605 collection and subsequent filtration of a smaller volume of water (21 L or $48 \mathrm{~L})$ at a single location

606 in a shorter period of time (minutes). The advantage of using the underway system is that

607 microplastic abundances over a larger spatial area can be quantified whilst the vessel is in transit.

608 By comparison, CTD sampling facilitates the quantification of microplastic abundance at specific

609 locations making it less likely to mask contamination hotspots. However, some of the major

610 limitations associated with CTD microplastic sampling are (i) the vessel must stop at sampling

611 stations to collect samples, (ii) deployment and retrieval of the rosette water sampler is time

612 consuming and, (iii) only small volumes of water can be collected in comparison to the underway

613 sampling. The limitation of filtering smaller volumes of water is twofold in that there can be (i)

614 false negatives whereby microplastics are not sampled despite being present in the environment

615 or, (ii) microplastics are found in the samples but scaling up to relevant units (particles $\mathrm{m}^{-3}$ ) has a 616 greater effect on microplastic abundances.

617 
618 One of the major challenges that investigators face when quantifying marine microplastic 619 abundance is sample contamination. In addition to employing strict measures to control 620 contamination during sampling and processing, it is important that checks are carried out to 621 quantify potential contamination of samples. For underway samples in the present study, although 622 method blanks were free of contamination by synthetic particles, a single synthetic fibre was found 623 in one air contamination check. In context, there were between $0-15$ synthetic particles in each 624 underway sample, with an average of 2 synthetic particles per sample. For CTD samples in the 625 present study, between 0 - 3 synthetic fibres were found in the method blanks. In context, between $6260-18$ synthetic particles were found per CTD sample $(21 \mathrm{~L}$ or $48 \mathrm{~L})$, with an average of 2 particles

627 per sample. In both cases, if contamination were an issue, its contribution to the reported 628 microplastic abundances in the present study would be substantial. However, the possibility of 629 airborne contamination in the actual underway samples is projected to be low since (i) $92 \%$ of the 630 air contamination checks (11 of the 12 petri dishes) were free of synthetic particles and, (ii) air 631 contamination checks had maximum exposure to the atmosphere while actual samples had 632 minimal exposure. With respect to the CTD samples, it is proposed that synthetic fibres in the 633 method blanks may have been introduced into the Niskin bottle during the transfer of Milli-Q water 634 or could have been present from the previous CTD cast and remained in the bottle due to 635 insufficient rinsing with Milli-Q water prior to the blank. This should not have been an issue for 636 the actual samples since Niskin bottles were rinsed during the downcast and were closed within 637 the water column thus preventing the possibility of airborne contamination. 
640 The present study demonstrated the pervasiveness of microplastics in sub-surface waters of the

641 Arctic Central Basin (ACB). Two independent sampling techniques led to the discovery of

642 microplastics in near surface waters of the Polar Mixed Layer (PML) i.e. at a single depth of 8.5

$643 \mathrm{~m}$ as well as throughout the water column i.e. at multiple depths $(8-4369 \mathrm{~m})$ of the ACB. Such

644 findings confirm that microplastics are entering the central Arctic Ocean, that they are being

645 vertically transported out of surface waters and that the water column is one of the reservoirs of 646 microplastics in this region. Presently, however, uncertainty exists regarding the actual

647 mechanisms responsible for the vertical transport of microplastics in the Arctic Ocean. Although

648 there was a predominance of fibrous microplastics, the majority of which were polyester, the exact

649 sources of microplastics to the Arctic Ocean remain unknown as they could have been introduced

650 to the ecosystem via long range transport processes or originated from more local sources. The

651 fact that the highest microplastic abundances were recorded in the PML nearer to the periphery of

652 the ACB suggests the influence of location-specific factors e.g. absence of sea ice, proximity to 653 microplastic sources, wind, etc. Knowledge about microplastic abundance, distribution and 654 composition in the Arctic Ocean is vital as it provides (i) quantitative data on the concentrations 655 and types of microplastics that polar organisms are exposed to, (ii) a sound starting point for 656 investigating the potential threat that microplastics pose to the Arctic ecosystem and, (iii) insight 657 into the whereabouts of the 'missing plastic' from oceanic surface waters.

659 Acknowledgements

660 The authors acknowledge the invaluable support of the staff of the Swedish Polar Research 661 Secretariat (especially Jeanette Axelsson, Robert Holden, Lars Lehnert, Asa Lindgren, Axel 662 Meiton and Per Salo) and the crew of icebreaker Oden with the Arctic Ocean 2016 expedition. The 
663 expert guidance of Mr. Andrew Tonkin (Plymouth University) during FT-IR analyses is also 664 acknowledged. The first author also acknowledges the support of fellow early career scientists 665 (especially Hans-Martin Heyn, Luz Maria Ramirez, Grace Shephard), other researchers (especially 666 Asa Johannisson, Sofi Jonsson, Michelle Nerentorp, Carina Johansson) and staff (especially Bengt 667 Berglund, Ted Juliusen) during the expedition.

668

$669 \quad$ Funding

670 Sampling in the Arctic Ocean was funded by the Swedish Polar Research Secretariat (SPRS) under 671 the Early Career Scientist (ECS) Programme in which the first author was a participant. This work 672 was also co-funded through a MARES Grant. MARES is a Joint Doctorate programme selected 673 under Erasmus Mundus and coordinated by Ghent University (FPA 2011-0016). The funders had 674 no role in study design, data collection, analysis and interpretation, decision to publish, or 675 preparation of the manuscript.

676

677 References

678 Amélineau, F., Bonnet, D., Heitz, O., Mortreux, V., Harding, A.M.A., Karnovsky, N., Walkusz, 679 W., Fort, J., Gremillet, D., 2016. Microplastic pollution in the Greenland Sea: Background levels 680 and selective contamination of planktivorous diving seabirds. Environmental Pollution 219, 1131$681 \quad 1139$.

682 Andrady, A.L., 2011. Microplastics in the marine environment. Marine Pollution Bulletin 62, 683 1596-1605.

684 Andrady, A.L., 2017. The plastic in microplastics: A review. Marine Pollution Bulletin 119, 1268522. 
Bagaev, A., Mizyuk, A., Khatmullina, L., Isachenko, I., Chubarenko, I., 2017. Anthropogenic fibres in the Baltic Sea water column: Field data, laboratory and numerical testing of their motion. Science of The Total Environment 599, 560-571.

Bergmann, M., Klages, M., 2012. Increase of litter at the Arctic deep-sea observatory HAUSGARTEN. Marine Pollution Bulletin 64, 2734-2741.

Bergmann, M., Sandhop, N., Schewe, I., D'Hert, D., 2016. Observations of floating anthropogenic litter in the Barents Sea and Fram Strait, Arctic. Polar Biology 39, 553-560.

Bergmann, M., Lutz, B., Tekman, M.B., Gutow, L., 2017a. Citizen scientists reveal: Marine litter pollutes Arctic beaches and affects wild life. Marine Pollution Bulletin 125, 535-540.

Bergmann, M., Wirzberger, V., Krumpen, T., Lorenz, C., Primpke, S., Tekman, M.B., Gerdts, G., 2017b. High Quantities of Microplastic in Arctic Deep-Sea Sediments from the HAUSGARTEN Observatory. Environmental Science \& Technology 51, 11000-11010.

Besseling, E., Wegner, A., Foekema, E.M., van den Heuvel-Greve, M.J., Koelmans, A.A., 2013. Effects of Microplastic on Fitness and PCB Bioaccumulation by the Lugworm Arenicola marina (L.). Environmental Science \& Technology 47, 593-600.

Besseling, E., Wang, B., Lurling, M., Koelmans, A.A., 2014. Nanoplastic Affects Growth of $S$. obliquus and Reproduction of D. magna. Environmental Science \& Technology 48, 12336-12343. Bhattacharya, P., Lin, S., Turner, J.P., Ke, P.C., 2010. Physical Adsorption of Charged Plastic Nanoparticles Affects Algal Photosynthesis. The Journal of Physical Chemistry C 114, 1655616561.

Browne, M.A., Crump, P., Niven, S.J., Teuten, E., Tonkin, A., Galloway, T., Thompson, R., 2011. Accumulation of Microplastic on Shorelines Woldwide: Sources and Sinks. Environmental Science \& Technology 45, 9175-9179. 
Cincinelli, A., Scopetani, C., Chelazzi, D., Lombardini, E., Martellini, T., Katsoyiannis, A., Fossi, M.C., Corsolini, S., 2017. Microplastic in the surface waters of the Ross Sea (Antarctica): Occurrence, distribution and characterization by FTIR. Chemosphere 175, 391-400.

Cole, M., Lindeque, P., Fileman, E., Halsband, C., Galloway, T.S., 2015. The Impact of Polystyrene Microplastics on Feeding, Function and Fecundity in the Marine Copepod Calanus helgolandicus. Environmental Science \& Technology 49, 1130-1137.

Cole, M., Lindeque, P.K., Fileman, E., Clark, J., Lewis, C., Halsband, C., Galloway, T.S., 2016. Microplastics Alter the Properties and Sinking Rates of Zooplankton Faecal Pellets. Environmental Science \& Technology 50, 3239-3246.

Comnea-Stancu, I.R., Wieland, K., Ramer, G., Schwaighofer, A., Lendl, B., 2017. On the Identification of Rayon/Viscose as a Major Fraction of Microplastics in the Marine Environment: Discrimination between Natural and Manmade Cellulosic Fibers Using Fourier Transform Infrared Spectroscopy. Applied Spectroscopy 71, 939-950.

Conservation of Arctic Flora and Fauna (CAFF), 2013. Arctic Biodiversity Assessment: Status and trends in Arctic biodiversity, in: Meltofte, H. (Ed.). Conservation of Arctic Flora and Fauna (CAFF), Akureyri, Iceland.

Conservation of Arctic Flora and Fauna (CAFF), 2017. State of the Arctic Marine Biodiversity Report. Conservation of Arctic Flora and Fauna International Secretariat, Akureyri, Iceland.

Courtene-Jones, W., Quinn, B., Gary, S.F., Mogg, A.O.M., Narayanaswamy, B.E., 2017. Microplastic pollution identified in deep-sea water and ingested by benthic invertebrates in the Rockall Trough, North Atlantic Ocean. Environmental Pollution 231, 271-280.

Cózar, A., Echevarria, F., Gonzalez-Gordillo, J.I., Irigoien, X., Ubeda, B., Hernandez-Leon, S., Palma, A.T., Navarro, S., Garcia-de-Lomas, J., Ruiz, A., Fernandez-de-Puelles, M.L., Duarte, 
732 C.M., 2014. Plastic debris in the open ocean. Proceedings of the National Academy of Sciences $733111,10239-10244$.

734 Cózar, A., Marti, E., Duarte, C.M., Garcia-de-Lomas, J., van Sebille, E., Ballatore, T.J., Eguiluz, 735 V.M., Gonzalez-Gordillo, J.I., Pedrotti, M.L., Echevarria, F., Trouble, R., Irigoien, X., 2017. The 736 Arctic Ocean as a dead end for floating plastics in the North Atlantic branch of the Thermohaline 737 Circulation. Science Advances 3:e1600582.

738 Desforges, J.-P.W., Galbraith, M., Dangerfield, N., Ross, P.S., 2014. Widespread distribution of 739 microplastics in subsurface seawater in the NE Pacific Ocean. Marine Pollution Bulletin 79, 9474099.

741 Dris, R., Gasperi, J., Saad, M., Mirande, C.c., Tassin, B., 2016. Synthetic fibers in atmospheric 742 fallout: A source of microplastics in the environment? Marine Pollution Bulletin 104, 290-293.

743 Enders, K., Lenz, R., Stedmon, C.A., Nielsen, T.G., 2015. Abundance, size and polymer 744 composition of marine microplastics $<10 \mu \mathrm{m}$ in the Atlantic Ocean and their modelled vertical 745 distribution. Marine Pollution Bulletin 100, 70-81.

746 Engel, A., Piontek, J., Metfies, K., Endres, S., Sprong, P., Peeken, I., Gabler-Schwarz, S., Nothig, 747 E.-M., 2017. Inter-annual variability of transparent exopolymer particles in the Arctic Ocean 748 reveals high sensitivity to ecosystem changes. Scientific Reports 7, 4129.

749 Eriksen, M., Lebreton, L.C.M., Carson, H.S., Thiel, M., Moore, C.J., Borerro, J.C., Galgani, F., 750 Ryan, P.G., Reisser, J., 2014. Plastic Pollution in the World's Oceans: More than 5 Trillion Plastic 751 Pieces Weighing over 250,000 Tons Afloat at Sea. PLoS ONE 9, e111913.

752 Fazey, F.M.C., Ryan, P.G., 2016. Biofouling on buoyant marine plastics: An experimental study 753 into the effect of size on surface longevity. Environmental Pollution 210, 354-360. 
754 Isobe, A., Uchiyama-Matsumoto, K., Uchida, K., Tokai, T., 2017. Microplastics in the Southern 755 Ocean. Marine Pollution Bulletin 114, 623-626.

756 Jakobsson., M., Grantz, A., Kristoffersen, Y., Macnab, R., MacDonald, R.W., Sakshaug, E., Stein, 757 R., Jokat, W., 2004. The Arctic Ocean: Boundary Conditions and Background Information, in: 758 Stein, R., MacDonald, R.W. (Eds.), The Organic Carbon Cycle in the Arctic Ocean. Springer, 759 Berlin.

760 Kanhai, L.D.K., Officer, R., Lyashevska, O., Thompson, R.C., O'Connor, I., 2017. Microplastic 761 abundance, distribution and composition along a latitudinal gradient in the Atlantic Ocean. Marine 762 Pollution Bulletin 115, 307-314.

763 Kuhn, S., Schaafsma, F.L., van Werven, B., Flores, H., Bergmann, M., Egelkraut-Holtus, M., 764 Tekman, M.B., van Franeker, J.A., 2018. Plastic ingestion by juvenile polar cod (Boreogadus 765 saida) in the Arctic Ocean. Polar Biology, 1-10.

766 Kukulka, T., Proskurowski, G., Morét-Ferguson, S., Meyer, D.W., Law, K.L.C.L., 2012. The 767 effect of wind mixing on the vertical distribution of buoyant plastic debris. Geophysical Research 768 Letters 39.

769 Long, M., Moriceau, B.1., Gallinari, M., Lambert, C., Huvet, A., Raffray, J., Soudant, P., 2015. 770 Interactions between microplastics and phytoplankton aggregates: Impact on their respective fates. 771 Marine Chemistry 175, 39-46.

772 Lusher, A.L., Burke, A., O'Connor, I., Officer, R., 2014. Microplastic pollution in the Northeast 773 Atlantic Ocean: Validated and opportunistic sampling. Marine Pollution Bulletin 88, 325-333.

774 Lusher, A.L., Tirelli, V., O'Connor, I., Officer, R., 2015. Microplastics in Arctic polar waters: the 775 first reported values of particles in surface and sub-surface samples. Scientific Reports 5, 1-9. 
776 Mallory, M.L., 2008. Marine plastic debris in northern fulmars from the Canadian high Arctic.

777 Marine Pollution Bulletin 56, 1501-1504.

778 Napper, I.E., Thompson, R.C., 2016. Release of synthetic microplastic plastic fibres from domestic 779 washing machines: Effects of fabric type and washing conditions. Marine Pollution Bulletin 112, $780 \quad 39-45$.

781 Obbard, R.W., Sadri, S., Wong, Y.Q., Khitun, A.A., Baker, I., Thompson, R.C.C.E.F., 2014. 782 Global warming releases microplastic legacy frozen in Arctic Sea ice. Earth's Future 2, 315-320.

783 Oliveira, M., Ribeiro, A., Hylland, K., Guilhermino, L., 2013. Single and combined effects of 784 microplastics and pyrene on juveniles (0+ group) of the common goby Pomatoschistus microps 785 (Teleostei, Gobiidae). Ecological Indicators 34, 641-647.

786 Phuong, N.N., Zalouk-Vergnoux, A., Poirier, L., Kamari, A., Chatel, A., Mouneyrac, C., Lagarde, 787 F., 2016. Is there any consistency between the microplastics found in the field and those used in 788 laboratory experiments? Environmental Pollution 211, 111-123.

789 Provencher, J.F., Gaston, A.J., Mallory, M.L., O'hara, P.D., Gilchrist, H.G., 2012. Ingested plastic 790 in a diving seabird, the thick-billed murre (Uria lomvia), in the eastern Canadian Arctic. Marine 791 Pollution Bulletin 60, 1406-1411.

792 R Core Team, 2015. R: A Language and Environment for Statistical Computing. R Foundation for 793 Statistical Computing Vienna, Austria.

794 Rochman, C.M., Hoh, E., Kurobe, T., Teh, S.J., 2013. Ingested plastic transfers hazardous 795 chemicals to fish and induces hepatic stress. Scientific Reports 3, 3263.

796 Rochman, C.M., Kurobe, T., Flores, I., Teh, S.J., 2014. Early warning signs of endocrine 797 disruption in adult fish from the ingestion of polyethylene with and without sorbed chemical 798 pollutants from the marine environment. Science of The Total Environment 493, 656-661. 
Rudels, B., Larsson, A.-M., Sehlstedt, P.-I., 1991. Stratification and water mass formation in the Arctic Ocean: some implications for the nutrient distribution. Polar Research 10, 19-32.

Rudels, B., 2015. Arctic Ocean circulation, processes and water masses: A description of observations and ideas with focus on the period prior to the International Polar Year 2007 - 2009. Progress in Oceanography 132, 22-67.

Tekman, M.B., Krumpen, T., Bergmann, M., 2017. Marine litter on deep Arctic seafloor continues to increase and spreads to the North at the HAUSGARTEN observatory. Deep Sea Research Part I: Oceanographic Research Papers 120, 88-99.

Trevail, A.M., Gabrielsen, G.W., Kuhn, S., Van Franeker, J.A., 2015. Elevated levels of ingested plastic in a high Arctic seabird, the northern fulmar (Fulmarus glacialis). Polar Biology 38, 975981.

United Nations Environment Programme (UNEP), 2011. UNEP Year Book: Emerging issues in our global environment. United Nations Environment Programme (UNEP), Nairobi, Kenya. van Sebille, E., England, M.H., Froyland, G., 2012. Origin, dynamics and evolution of ocean garbage patches from observed surface drifters Environmental Research Letters 7, 1-6.

von Moos, N., Burkhardt-Holm, P., Kohler, A., 2012. Uptake and Effects of Microplastics on Cells and Tissue of the Blue Mussel Mytilus edulis L. after an Experimental Exposure. Environmental Science \& Technology 46, 11327-11335.

Waller, C.L., Griffiths, H.J., Waluda, C.M., Thorpe, S.E., Loaiza, I., Moreno, B., Pacherres, C.O., Hughes, K.A., 2017. Microplastics in the Antarctic marine system: An emerging area of research. Science of The Total Environment 598, 220-227. 
820 Wegner, A., Besseling, E., Foekema, E.M., Kamermans, P., Koelmans, A.A., 2012. Effects of

821 Nanopolystyrene on the Feeding Behaviour of the Blue mussel (Mytilus Edulis L.). Environmental

822 Toxicology and Chemistry 31, 2490-2497.

823 Wright, S.L., Rowe, D., Thompson, R.C., Galloway, T.S., 2013. Microplastic ingestion decreases

824 energy reserves in marine worms. Current Biology 23, R1031-R1033.

825 Zarfl, C., Matthies, M., 2010. Are marine plastic particles transport vectors for organic pollutants 826 to the Arctic? Marine Pollution Bulletin 60, 1810-1814.

827

$828 \quad$ List of Tables

829 Table 1: Microplastic abundance in the various water layers of the Arctic Central Basin (ACB)

830

$831 \quad$ List of Figures

832 Figure 1: General overview of the bathymetry and water masses of the Arctic Central Basin 833 [reprinted here with permission from CAFF], (CAFF 2013)

834 Figure 2: Microplastic abundance in the Arctic Central Basin (a) based on bow water sampling at 835 a single depth of $8.5 \mathrm{~m}$, (b) based on CTD sampling at multiple depths $(8-4369 \mathrm{~m})$

836 Figure 3: Colours of microplastics found in (a) underway and (b) CTD samples at depths $8-4369$ $837 \mathrm{~m}$

838 Figure 4: Size classes of microplastics found in (a) underway and (b) CTD samples at depths 8 $8394369 \mathrm{~m}$

840 Figure 5: Synthetic polymers found in (a) underway and (b) CTD samples at depths $8-4369 \mathrm{~m}$

841 Figure 6: Microplastic abundance from the various CTD casts in the Arctic Ocean 842 


\section{$843 \quad$ List of Supplementary Tables}

844 Supplementary Table 1: Descriptive statistics, tests of normality and correlation findings for 845 environmental variables (underway data)

846 Supplementary Table 2: Descriptive statistics, tests of normality and correlation findings for 847 environmental variables (CTD data)

848 Supplementary Table 3: Quality control checks associated with the underway sampling

849 Supplementary Table 4: Quality control checks associated with CTD sampling

850 Supplementary Table 5: Number of microplastics and calculated microplastic abundances for the 851 underway samples

852 Supplementary Table 6: Number of microplastics and calculated microplastic abundances for 853 each CTD cast

854 Supplementary Table 7: Microplastic abundances reported for oceanic basins across the world 855 